\title{
Identifying a Site for Maximum Delivery of Oxygen to Transplanted Cells*
}

\author{
SHUBJEET KAUR, M.D., JOAQUIN CORTIELLA, M.D., \\ and CHARLES A. VACANTI, M.D.
}

\begin{abstract}
For in vivo cell implantation techniques to be successful, the energy and metabolic substrate requirement of the cells being grown must be met. Certain cells with high-energy requirements (e.g., hepatocytes, pancreatic island cells) experience a high degree of cell death after implantation due to a limited supply of oxygen. We proposed that the pleural cavity might be an oxygen-rich environment and hence an excellent site for cell implantation. To test the hypothesis that the delivery of oxygen to the pleural cavity is directly proportional to the inspired oxygen concentration we measured the $\mathrm{pO}_{2}$ of saline instilled in the pleural cavity as compared to that of the peritoneal cavity. We postulated that the physiologic basis for any difference was the result of direct diffusion of oxygen into the pleural space across the alveoli. The study was conducted on sheep $(n=6)$, after induction of general anesthesia, in two phases, control and experimental. Saline was instilled into the peritoneal and pleural cavities via catheters. after equilibration at given $\mathrm{FiO}_{2}$, the $\mathrm{pO}_{2}$ of the paline aspirated from the two cavities was compared. In the experimental group, animals were sacrificed (no circulation) and ventilated. The same sequence of steps as in the control phase were repeated. In the control group, the $\mathrm{pO}_{2}$ of saline aspirated from the pleural cavity approached the arterial $\mathrm{pO}_{2}$ at all $\mathrm{FiO}_{2}$ levels. The $\mathrm{pO}_{2}$ of the peritoneal saline aspirate fell over time. In the experimental phase (no circulation), the $\mathrm{pO}_{2}$ of the pleural cavity saline rose to $>400 \mathrm{mmHg}$. We conclude that this is a result of direct diffusion and is a potential source of unlimited oxygen supply not dependent on vascular supply.
\end{abstract}

\section{INTRODUCTION}

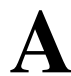
s applications for engineered tissues develop, one barrier to cell survival is optimization of the supply of oxygen to cells immediately upon implantation. Some cell types have a very low metabolic rate and will survive in a relatively hypoxic environment until a vascular supply can be established. Other cell types with high-energy requirements (e.g., hepatocyte, pancreatic islet cells) may have a better survival if they are immediately implanted into an oxygen-rich environment. These cell types may experience a high degree of cell death if this oxygen requirement is not met. We tested the hypothesis that the pleural cavity

Department of Anesthesiology, UMass Memorial Medical Center, Worcester, Massachusetts.

*Presented in part at the Annual Meeting of the Association of University Anesthesiologis ts, Washington DC, April 17-20, 1997. 
KAUR ET AL.

Table 1. Gas Analysis of Saline Samples Aspirated from the Abdominal Cavity as a Function of Time $\left(\mathrm{FiO}_{2}\right.$ 0.70) in Control Group Animals

\begin{tabular}{lccccc}
\hline & 0 & 5 min & 25 min & 35 min & 45 min \\
Time & $($ mean \pm SEM $)$ & $($ mean \pm SEM $)$ & $($ mean \pm SEM $)$ & $($ mean \pm SEM $)$ & \begin{tabular}{c} 
(mean \pm SEM $)$ \\
\hline $\mathrm{pH}$
\end{tabular} \\
$\mathrm{pCO}_{2}$ & $6.85 \pm 0.070$ & $6.8 \pm 0.071$ & $6.58 \pm 0.047$ & $6.51 \pm 0.040$ & $6.47 \pm 0.028$ \\
$\mathrm{pO}_{2}$ & $102.83 \pm 4.96$ & $22.33 \pm 5.68$ & $74.33 \pm 3.78$ & $118.66 \pm 5.23$ & $154.83 \pm 3.4$ \\
\hline
\end{tabular}

$\mathrm{pO}_{2}$ and $\mathrm{pCO}_{2}$ values reported are in $\mathrm{mm}$ of $\mathrm{Hg}$.

may provide such an oxygen-rich milieu. Furthermore, it was previously believed that gas delivery to any body cavity is a function of its vascular supply. ${ }^{1,2} \mathrm{We}$ proposed that this is not the case, that instead oxygen diffuses directly through the lung tissue into the pleural space and its delivery is independent of vascular supply. If indeed this were true, the concentration of oxygen delivered to cell implants in the chest cavity (pleural space) could (1) be easily manipulated by adjusting the concentration of inspired oxygen, and (2) its supply would be virtually unlimited, similar to the environment in an incubator, with oxygen diffusing down a concentration gradient to the cells, as it is metabolized, rather than being dependent on blood supply that is disrupted and seriously impaired when the cells are implanted elsewhere in the body.

\section{MATERIAL AND METHODS}

The study design was reviewed and approved by our Institutional Animal Studies Review Committee in accordance with APS/NIH guidelines. A total of six sheep (average weight $50 \mathrm{~kg}$ ) were studied in two phases; a control group was studied as described below. The same animals were then allowed to reequilibrate and then sacrificed and studied in an identical manner as the experimental group. In the control group, general anesthesia was induced with intramuscular xylazine and ketamine and the animals paralyzed with pancuronium. After endotracheal intubation ( 9.0 i.d.), the animals were placed on controlled ventilation (Ohmeda 7000 Ventilator) and anesthesia was maintained with isoflurane. A 14-gauge catheter was placed in the femoral artery and baseline arterial blood gas analysis was performed (Instrumentation Laboratories $16 / 40 \mathrm{pH}$, Blood Gas, Electrolytes Analyzer, Lexington, MA) while the animals were ventilated with $100 \%$ oxygen. A 20-gauge catheter (PerFix Epidural Anesthesia Set, Braun Medical Inc., Bethlehem, PA) was then advanced into the peritoneal cavity just lateral to the umbilicus. A similar catheter was placed in the right pleural cavity in the fifth intercostal space in the midaxillary line. The blood gas analysis was repeated to document that there was no change from baseline reflecting lung injury secondary to pleural catheter placement. Animals were then ventilated with an $\mathrm{FiO}_{2}$ of $0.25 \%$, and $50 \mathrm{cc}$ of normal saline was injected via the previously placed catheters into each cavity. After allowing $10 \mathrm{~min}$ for equilibration (based on prior preliminary experiment data, not reported), saline samples $(0.5$ to $1 \mathrm{cc})$ were aspirated from each body cavity as well as the arterial catheter for analysis of $\mathrm{pH}, \mathrm{pO}_{2}$, and $\mathrm{pCO}_{2}$. The sheep were then ventilated with increasing inspired oxygen concentrations $(0.25,0.45,0.70,100 \%)$ in a stepwise manner (control phase),

Table 2. Gas Analysis of Saline Aspirated from Pleural Space as a Function of Time $\left(\mathrm{FiO}_{2}\right.$ 0.70)-Control Phase

\begin{tabular}{|c|c|c|c|c|c|}
\hline Time & $\begin{array}{c}0 \\
(\text { mean } \pm S E M)\end{array}$ & $\begin{array}{c}5 \text { min } \\
(\text { mean } \pm S E M)\end{array}$ & $\begin{array}{c}25 \mathrm{~min} \\
(\text { mean } \pm S E M)\end{array}$ & $\begin{array}{c}35 \text { min } \\
(\text { mean } \pm S E M)\end{array}$ & $\begin{array}{c}45 \min \\
(\text { mean } \pm S E M)\end{array}$ \\
\hline $\mathrm{pH}$ & $6.9 \pm 0.121$ & $6.91 \pm 0.034$ & $6.88 \pm 0.03$ & $6.91 \pm 0.047$ & $6.91 \pm 0.016$ \\
\hline $\mathrm{pCO}_{2}$ & $19.25 \pm 1.662$ & $20 \pm 4.139$ & $35.66 \pm 2.34$ & $40.66 \pm 0.98$ & $43 \pm 0.955$ \\
\hline $\mathrm{pO}_{2}$ & $180.16 \pm 17.98$ & $157 \pm 7.47$ & $202 \pm 2.37$ & $349 \pm 6.6$ & $431.50 \pm 3.46$ \\
\hline
\end{tabular}

$\mathrm{pCO}_{2}$ and $\mathrm{pO}_{2}$ values reported are in $\mathrm{mm}$ of $\mathrm{Hg}$. 
MAXIMUM OXYGEN DELIVERY TO TRANSPLANTED CELLS

Table 3. Comparison of pO 2 (mmg) of Pleural Versus Peritoneal Aspirates at Varying FiO $_{2}$ During Control Phase (Ventilation plus Circulation)

\begin{tabular}{|c|c|c|c|c|}
\hline $\mathrm{FiO} 2$ & $\begin{array}{c}100 \% \\
(\text { mean } \pm \text { SEM) }\end{array}$ & $\begin{array}{c}70 \% \\
(\text { mean } \pm \text { SEM) }\end{array}$ & $\begin{array}{c}45 \% \\
(\text { mean } \pm \text { SEM) }\end{array}$ & $\begin{array}{c}25 \% \\
(\text { mean } \pm S E M)\end{array}$ \\
\hline \multicolumn{5}{|c|}{ Pleural aspirate } \\
\hline \multicolumn{4}{|c|}{ Peritoneal aspirate } & $188.60 \pm 19.09$ \\
\hline $\mathrm{pO}_{2}$ & $62.50 \pm 7.93$ & $57.20 \pm 8.93$ & $77.40 \pm 19.10$ & $68.00 \pm 13.30$ \\
\hline$p$ Value & $<0.001^{*}$ & $<0.001^{*}$ & $p=0.004^{*}$ & $<0.001^{*}$ \\
\hline
\end{tabular}

${ }^{*} p$ value statistically significant.

allowing 5-10 min at each stage for reequilibration. The analysis of $\mathrm{pH}, \mathrm{pO}_{2}$, and $\mathrm{pCO}_{2}$ was repeated at each inspired oxygen concentration. At an $\mathrm{FiO}_{2}$ of $70 \%$ the $\mathrm{pH}, \mathrm{pO}_{2}$, and $\mathrm{pCO}_{2}$ of both the pleural and peritoneal saline aspirate was analyzed at time points of 5, 25, 35, and $45 \mathrm{~min}$. The animals were ventilated on room air with an $\mathrm{FiO}_{2}$ of $0.25 \%$ until equilibration.

At this time the experimental phase of the study began. The animals were sacrificed by intravenous pentobarbital injection. Ventilation was continued with a stepwise increase in inspired oxygen concentration after cardiac arrest (no circulation). Saline samples were aspirated from each body cavity and analyzed for $\mathrm{pH}, \mathrm{pCO}_{2}$, and $\mathrm{pO}_{2}$ for this phase of the study.

A detailed statistical analysis and comparison using Student's $t$-test was performed between the mean value of the $\mathrm{pO}_{2}$ of the saline aspirate from the pleural versus the peritoneal cavity at four different inspired oxygen concentrations (for $0.25 \%, 0.45 \%, 0.75 \%, 100 \%$ ).

\section{RESULTS}

The baseline values for arterial blood were a $\mathrm{pH}$ of $7.6 \mathrm{pCO}_{2}$ of 26 and a $\mathrm{pO}_{2}$ of 148 . For the pleural cavity saline aspirate, the $\mathrm{pH}$ was $7.15 \mathrm{pCO}_{2} 22.9$ and $\mathrm{pO}_{2}$ was 226 . The peritoneal saline aspirate showed a $\mathrm{pH} 7.18, \mathrm{pCO}_{2} 18 \mathrm{pO}_{2}$ of 44 .

In the control group (i.e., animals with circulation and ventilation), the peritoneal saline aspirate analysis on an inspired $\mathrm{FiO}_{2}$ of $70 \%$ was analyzed sequentially over a period of $45 \mathrm{~min}$. The results are demonstrated in Table 1 and show that the $\mathrm{pO}_{2}$ of the saline aspirated from the peritoneal cavity, during the control phase, decreased from a peak of $156 \mathrm{mmHg}$ to $2 \mathrm{mmHg}$ over $45 \mathrm{~min}$. During the same time period of the control phase of the experiment, the $\mathrm{pO}_{2}$ of saline aspirated from pleural space rose from $165 \mathrm{mmHg}$ to $433 \mathrm{mmHg}$, as shown in Table 2. The $\mathrm{pO}_{2}$ of the pleural cavity saline aspirate approximated or was greater than the arterial $\mathrm{pO}_{2}$ at all $\mathrm{FiO}_{2}$ levels. Comparison of the $\mathrm{pO}_{2}$ of the saline aspirate from the pleural versus peritoneal cavity at various inspired oxygen concentrations during the control phase of the experiment is summarized in Table 3 . The pleural saline $\mathrm{pO}_{2}$ was consistently higher than the peritoneal aspirate and this difference was statistically significant at all levels of $\mathrm{FiO}_{2}(p<0.001)$.

In the experimental phase (ventilation without circulation) the $\mathrm{pO}_{2}$ of the pleural aspirate, at an $\mathrm{FiO}_{2}$ of $.70 \%$ is shown (Table 4) in comparison to the pleural saline aspirate $\mathrm{pO}_{2}$ at the same $\mathrm{FiO}_{2}$ in the control phase (animal alive). The two values were comparable.

Table 4. Comparison of the pO 2 of Pleural Cavity Saline Aspirate at an $\mathrm{FiO}_{2}$ of $70 \%$ in the Control Versus Experimental Phase $(p=0.001)^{a}$

$($ mean $\pm \mathrm{SEM})$

Control phase

$209.00 \pm 19.37$

Experimental phase

$367.00 \pm 25.57$

${ }^{\mathrm{a}}$ Statistically significant. 


\section{DISCUSSION}

It has been previously believed that gas delivery to any body cavity is dependent on its vascular supply. ${ }^{1,2}$ Our findings refute this long-held belief. Our results demonstrate that the partial pressure of oxygen in the pleural space is a function of the inspired oxygen concentration and independent of circulation (vascular delivery). The $\mathrm{pO}_{2}$ of the saline aspirated from the pleural cavity approached the arterial $\mathrm{pO}_{2}$ at all $\mathrm{FiO}_{2}$ levels. Increasing the inspired oxygen concentration can easily increase the concentration of oxygen in the pleural cavity. This can result in a virtually unlimited supply of oxygen in the pleural space. The pleural space may mimic the environment in an incubator and provide the ideal in vivo environment for growth of cells with a high metabolic need. This can result in a significantly higher survival ratio for cells implanted in this cavity.

In contrast to the pleural space, the $\mathrm{pO}_{2}$ of the saline aspirate from the peritoneal cavity fell over time (possibly secondary to local consumption or diffusion into the intestines). Furthermore, in the experimental phase, even after the animal was sacrificed (i.e., no circulation/vascular delivery, but ongoing ventilation), the $\mathrm{pO}_{2}$ of the pleural cavity aspirate increased with increasing $\mathrm{FiO}_{2}$. The high $\mathrm{pO}_{2}$ of the pleural cavity aspirate in the second phase of the experiment can only be accounted for by direct diffusion of oxygen from the alveoli to the pleural cavity across a concentration gradient.

In conclusion, our study has identified a high oxygen availability site for in vivo cell growth and established direct diffusion to be the mechanism responsible for transfer of oxygen from the alveoli to the pleural space. The size of the pleural space (in the clinical setting of an expanded lung) may be a limiting factor for the cell mass that may be grown in it. Further experiments are needed to define this issue. Cells may be grown in the pleural space for subsequent transplantation in other body sites or as a permanent implant, e.g., hepatocytes in the right pleural space. This opens areas for further investigation and research.

\section{REFERENCES}

1. Tenney, S.M., Carpenter, F.G., and Rahn, M. Gas transfers in a sulfur hexafluoride pneumoperitoneu m. J. Appl. Physiol. 6, 201, 1953.

2. Eger, E.I., and Saidman, L.J. Hazards of nitrous oxide anesthesia in bowel obstruction and pneumothorax. Anesthesiology 26, 61, 1965 .

Address reprint requests to: Shubjeet Kaur, M.D. Department of Anesthesiology UMass Memorial Medical Center 55 Lake Avenue, North Worcester, MA 01655

E-mail: shubjeet.Kaur@umassmed.edu 